\title{
Spatial Location of Regional Resources within the Strategic Drift of Globalization: Problems, Tendencies, Procedures
}

\author{
N.G. Yushkova ${ }^{1, *}$, E.G. Gushchina ${ }^{1}$ and A.V. Shokhneh ${ }^{2}$ \\ *Corresponding author: ymanul@gmail.com \\ ${ }^{1}$ Volgograd State Technical University, Volgograd, Russia \\ ${ }^{2}$ Volgograd State Social and Pedagogical University, Volgograd, Russia
}

\begin{abstract}
From the beginning of the XXI century between the processes of regional systems globalization and location development resources bigger contradictions can be seen. Balanced spatial development of territories is in ideal concepts and models for economics and society formation. But their implementation is under the influence of risks and threads. The uncial properties of regional systems are underestimated and their resource potential is used not reasonably. Thereby the strategic drift of globalization itself becomes not the fillip, but thread of perspective regional systems development. This investigation is dedicated to grounding ways to overcome its negative influence. Within this investigation we formulate a problem of global order tendencies analyses; development of new management tasks, including the formats of institutional norms, transforming the process of reproduction; forming of adaptive space reorganization procedure considering the lack of localized resources factor. Scientific novelty of the investigation is on optimization of the actual methods and tools for strategic management the territories and grounding the perspectives regional systems polistructural modelling. This allows to reduce strategic drift of globalization risks, modify regional economics evolution driving force and decrease human resources investigation process turbulence, assets, plots of land, preserve the integrality of the formed space and minimize its disbalance.
\end{abstract}

Keywords: regional system, strategic drift of globalization, sustainability, innovation, spatial development, collaborations.

\section{Introduction}

Strategic drift of globalization stops development of relations that are formed at different civilization and social and cultural periods of time. That causes uncontrolled social and cultural and political expanding of space: it becomes mostly fantasy environment. To form the real vital activity environment we need sources - resources. They define spatial localization of regional relations.

Defining of regional resources features is the basis for prognoses and strategies of spatial development. These features detect regional systems readiness for transition to the new technological paradigm and forming of digital economics. It defines the elaboration new management rules and that is ways for regional systems integration into their spatial co-existence within the limited resources conditions. Thus spatial localization of resources becomes the special form of cooperation for regional systems that provides exit from strategic drift of globalization.

\section{Problem Statement}

Until now within the existing theoretical and methodological approaches to investigation of spatial development of regional systems problems universal solutions that can be implemented for regional systems with different dynamics of social and economic processes for leaders and outsiders are not elaborated. The specific problems and features for regions-outsiders development are defined not only localization and lack of availability of resources but as well with low effectiveness of the implemented tools to manage the territory. Consequently, there is stagnation of progressive trends of globalization, cooling down the innovatization of regional systems spatial organization, that doesn't provide regularity and progress of their social and economic growth.

\section{Research Questions}

1. Defining of the strategic drift of globalization content as set of factors, expanding the potentials of regional systems spatial development or restricting this process.

2. Detecting common factors and priorities of regional resources localization as conditions to form concepts and strategies of regional systems spatial development.

3. Defining ways for interrelation of the steadiness and innovation processes at different stages of regional resources localization evolution as polistructural modelling basics. 


\section{Purpose of the Study}

The investigation hold is oriented on complex of special stabilizing and preventive measures development, they decrease globalization strategic drift risks and weaken grade of its influence on regional systems spatial development processes. Aggregated amount of developed measures establishes forming regional resources spatial organization, adapted for the conditions and priorities of long-term regions development. This procedure is able to combine global megatrends with steadiness and innovation principles due to their harmonization within the specific components and sub-systems. At the result, the actual regional strategizing system is optimized via synchronization of social and economic processes of renovation and spatial form, causes by them.

\section{Research Methods}

Deduction and induction, synthesis and analyses of modern ideas on great variety of spatial objects methods, as well as existence of virtual spaces, that allowed defining school "spatial development of economic systems" via the philosophical system of ontology are used in the article. Ontology of philosophy methods let us form theoretical and methodological system of spatial development considering the contradictions of essential catalepsy and behavioral subjective in particular.

\section{Findings}

\subsection{Strategic drift of globalization: restrictions and abilities of spatial development}

Origin of the idea "spatial development" is the result of mankind evolution reactivity in the XX century, integration of many science branches, origin of institutional and interdisciplinary approaches to the investigations. As the result, spatial development hardly corresponds to organization of economic functioning processes and the ideas on multidimensionality and discretion of space constantly develop. In modern conditions this process is influenced by fractality, great variety of spatial objects as well as ability of virtual spaces existence [1].

Certain ideas on space as universal way for learning great variety of systems are changed by complexity and great variety of this process description. This approach provides some requirements for economic rebalancing, reducing of possible turbulence that obliges to form strict scientific ideas on spatial development of systems. This is necessary condition for development preventive means for prevention risks for strategic drift of globalizations and their demonstrations as prolonged crises [2].

Constructiveness of the existing processes reduces due to the absence of the unified approaches (technologies), allowing optimally combine factors of limited resources and their location with providing progressive changes for organization of space, regulated by "knowledge economics". State authorities and public efforts are oriented on neutralization of negative developments. Hence principles for synchronization of spatial development of regions and territories are increased. They are formalized within the content of territories development local strategies, regulating the full scope of their implementation. Thus the backgrounds for overcoming the strategic grift of globalization are formed.

\subsection{Localization of regional resources within the strategy forming system}

Increasing tendencies of globalization are directly connected with megatrends. Total expansion of megatrends was predicted at the end of XX century by J. Neisbit [3] and was explained by their phenomenological nature, large scale and ability to expand their influence on outer territories. In the XXI century their importance constantly increases with the adoptions of the society to the challenges of new technological order. They demonstrate the main ideas of regional systems economic and social changes [4]. According to modern scientific assessments globalization is one of the main megatrends, accompanied by globally increasing economic integration [5].

Along with globalization there are characterized the following megatrends:

- transition to "knowledge society";

- demographic changes;

- accelerating technological development;

- growth of "rarity of resources";

- changes of climate;

- increasing of global responsibility value;

- Internet forming of social and economic processes [6].

Under the globalization influence there can be other demonstrations in territorial systems as for territorial level of their organization [7]. Among them are [8]: defining and fixing of new competitive advantages, based on full resource potential use; defining ways for quantitative description of local competitive advantages that require systematization and development of special means for their comprehensive coverage and reasonable use. 
Regional competitive ability within the globalization in general in modern investigation is considered as: preparedness to reach challenges of global environment [9];

ability to elaborate and fix in space personified ways of changing famous, traditional and standardized ways for social and economic processes accumulation [10];

presence of reserves for searching and protection of local competitive abilities, defined by historical [11], ethical [12], natural [13], geographical [14], urbanistic, culture studies, technological and other features.

But the fact that regional systems have got the set of different advantages doesn't mean that they can achieve the nominal competitive positions. It is necessary, that the procedure for their usage meet the reproduction of knowledges and modern technologies [15] standards, as basic condition for forming global economics [16].

Regional systems competitive abilities within the localization of resources are considered to be factor of spatial strategy forming functioning results system at all hierarchy levels for territories management. First, it provided by accuracy of global order tendencies translation including the formats of institutional norms, and secondly, by the regional systems inner and outer relations and factors trends development with their identity preservation. It is the basis for polifunctional modelling of regional systems potential.

Thus regional systems competitive abilities is considered fists as condition to decrease influence of risks and threads of involvement into mainstream, regulated by globalization [17]. The authors grounded the positioning of competitive abilities as result of localization of regional systems spatial development, that has got different scenario, variants and forms of global and local approaches combination [18].

The regional development tendencies and their specifications, detected by the authors become ground for forming spatial localization of regional resources model.

\subsection{Steadiness and innovation processes collaboration is the basis for polistructural regional development modelling}

Forming resources localization means is connected with collaboration effects [5], combining the steadiness and innovation features. The idea of regional systems spatial development vectors is based on detecting these features. Depending on which vectors have the priority, localization of regional resources are managed via collaboration of regional systems specific subsystems.

The subsystem is the regional system steady features holder, reflecting the evolutional school for spatial development. It is classified at the level of strategic management and is the strategic insurance for preservation and successive development of the most value system formats, functions and forms. Due to this system framework this system exists. Simultaneously, constant reproduction for basic elements and interrelations doesn't disrupt the balance of the system functioning, doesn't falsify the objectives of strategizing.

The subsystem is the bearer of regional system innovative features and is classified at the project and program management level. It provides the spatial development revolutionary formats and forms due to implementation the principle: "locality-zoning-objectiveness and specificity". It is suggested, that the newly formed elements, corresponding to the innovation processes are able to fill in the framework cells. But they conflict with each other. This subsystem provides the system adaptive reaction on the new processes influence via their forms and interrelations. They are fixed in the space due to special tools [19]. The tools increase the conflict-free coexistence of innovative and steady elements ability for its synchronization with institutional environment via constant reproduction of basic elements and system interrelations.

Collaboration process effectiveness can be evaluated by regional systems dynamism reorganization grade within implemented spatial concepts [20]. Reorganization can be fixed in structural as well as in regional systems infrastructural changes, due to economic agent's interrelation [21]. The authors' earlier investigations results [19] prove increasing role of the infrastructural priorities within the regional development processes due to enhancement of the adaption function. As collaboration and implementation of infrastructure principles are integral, typological regional systems renovation space is obligatory. At the result of their implementation, there should be formed objects - new economic activity features bearers together with regional economics traditional objects.

The newly formed objects within the regional systems require ranking, predetermining perspective processes for transformation at their territorial allegiance. Particularly, in perspective, regional systems development based on local resources use, can become more complicated, bigger and be differentiated. Hence, infrastructural priorities within the regional systems designate changes of the required dynamics. It lets them become the influence factor on the changeability of vital functions environment grade.

Considering the collaboration objective laws, mentioned above the system of strategizing of spatial development is improving [22]. But only negative factors reflecting are not enough for it. It is necessary to anticipate potentially possible adverse changes and be able to withstand them. That is why it is reasonable to appeal to forsite technologies, allowing control regional development dynamic via modelling of processes.

A local resource for development usage optimization procedure, suggested by the authors, increases the adaptiveness of strategizing. It is defined by steadiness and innovation factors harmonization parameters at development of regional development strategies. Communications maps of strategies practical implementation are done considering time factor, and their means are differentiated according to set of individual territories specifications, including location of resources. Minimization strategy of potential risks and threads for regional systems development is based on these conceptual provisions, and regulation function of governing authorities gets the increasing meaning. 


\section{Conclusion}

The modern society is at the stage of changing development paradigms, constructed on expanding of scientific knowledge on global space. Regional systems classifying evolution stages are defined by presence or absence of conflicts between the priorities and objective rules or regional resources usage. The specifications of these stages are founded on the principles and ways of resources spatial location, which arise due to implementation of development priorities, become the plane of social and economic processes at the formed regional systems space.

The globalization process supposes achieving of social and cultural synchronization within the regions spatial development and designing the local strategies, would surely go beyond their physic, political and territorial boundaries. That causes the inharmony, enhancing the strategic drift state, combining the synthetic sense of spatial development processes. Therewith the globalization is the non-reversible tendency of global society development.

This determines the analyses and synthesis of ideological sharpening and situations at the beginning of the XXI century, which are connected with the transition of the society to the new technological order. The anticipated transition requires progressive social and economic changes, new managing concepts, that are based on integration of spatial and organization systems. That is very important when the resources are limited. The governing transparency principle and total control should be balances of resources concepts localization for regional systems development.

Among the new factors of regional systems balanced development can be classified clear territorial and ethnical peculiarities while production, consuming, changing and distribution processes. The objective laws of spatial localization for regional systems development are bases on detecting the territories potential, system analyses of tendencies, defining the ways of their unification. Controlling and measuring priorities and regional systems objective laws development is suggested to be considered as the way to leave strategic drift of globalization.

The investigated provisions define the necessity to provide spatial steadiness of the controlling influence. It stipulates regional systems balancing and increasing steadiness, as well as functions and relations balance preservation via resources spatial location. Other regional systems factors influence results mostly infrastructural transformations; it has got new features and specifications. They affect ways to distribute functions, tightness of relations and intensity of processes.

Thus regional systems infrastructure components are able to become spatial regulator of social and economic processes. For this purpose we need strategic orientation at the territorial resources localization and the completeness of social, economic and ecological components consideration. This assembly is able to provide cycle nature of the regional potential reproduction processes within the spatial economics system and regional imbalance essential decreasing.

Constant value increasing for regional systems tasks balanced development causes development of preventive procedures for strategic management of spatial resources location. For this purpose it is reasonable to use progressive strategizing technologies, such as, for example, the forsite. They are able to increase planning, forecasting and controlling changes quality at the regional systems provide decreasing polarization of social and economic state due to leveling of heterogeneity of certain regional systems and their groups development. That explains the necessity for grounding the concepts and scenario of regional systems evaluation system in the way when considering existing great variety define optimal forms or their reorganization, stipulating first of all, increasing population quality of life.

\section{References}

1. A.F. Rogachev, E.V. Melikhova, A.V. Shokhnekh, Information technology of cognitive modeling of industrial and investment self-development of the medium-sized and single-industry towns. Espacios, 38(27), 4. URL: http://www.revistaespacios.com/a17v38n27/a17v38n27p04.pdf (2017).

2. W.I. Robinson, The theory of global capitalism and the emergence of transnational elites. Critical Sociology, 38(3). 349-363. DOI: 10.1177/0896920511411592 (2012).

3. J. Naisbitt, Megatrends: Ten new directions transforming our lives. New York, NY: Warner Books (1982).

4. R.D. Kamara, Creating enhanced capacity for local economic development (LED) through collaborative governance in South Africa. Socio Economic Challenges, 1(3), 98-115. URL: http://essuir.sumdu.edu.ua/handle/123456789/61739 (2017).

5. B. Schwenker, T. Raffel, Thoughts: Megatrends. München: Roland Berger School of Strategy and Economics (2012).

6. Reiss, M. Boundaries of «unlimited» enterprises: Prospects of network organizations. Problems of Theory and Practice of Management, 1, 92-97. (1997). [in Rus.].

7. C. Brăgaru, Local economic development (LED) planning in the face of globalization. Romanian Review of Social Sciences, 7(12). 15-28 (2017).

8. H.Angelo, D. Wachsmuth, Urbanizing urban political ecology: A critique of methodological cityism. International Journal of Urban and Regional Research, 39(1), 16-27. DOI: 10.1111 / 1468-2427.12105 (2015).

9. S.D. Kozlov, Globalization and regionalization, localization and glocalization: Some issues of research and teaching methodology. Problems of Modern Science and Education, 1(121), 64-71 (2018). [in Rus.].

10. R. Robertson, Glocalization: Time-space and homogeneity-heterogeneity. In M. Featherstone, S. Lash \& R. Robertson (Eds.), Global modernities (pp. 25-44). London: Sage Publications (1995). 
11. P. Kline, E. Moretti, Local economic development, agglomeration economies, and the big push: 100 years of evidence from the Tennessee valley authority. Quarterly Journal of Economics, 129(1), 275-331. DOI: 10.3386 / w19293 (2014).

12. D. Mijačić, Strategic planning of local economic development in Vojvodina. In: W. Bartlett, S. Maleković \& V. Monastiriotis (Ed.), Decentralization and local development in South-Eastern Europe. Research in transition (pp.179-195). London: Palgrave Macmillan (2013).

13. A.H. Namangaya, Urban spatial planning and local economic development: comparative assessment of practice in Tanzanian Cities. International Journal of Business, Humanities and Technology, 4(6), 20-31. URL: http://www.ijbhtnet.com/journals/Vol_4_No_6_December_2014/5.pdf (2014).

14. L. Shannon, Local economic development. An overview of the economic development role of local authorities in selected jurisdictions. Local government research series, 13. Dublin: Institute of Public Administration. URL: https://www.ipa.ie/_fileUpload/Documents/LocalEconomicDev_2018.pdf (2018).

15. G.R. Khasaev, V.A. Tsybatov, Tooling of modeling and strategic planning of energy-efficient development of the regional fuel and energy complex. Eurasian Journal of Analytical Chemistry, 12(7), 1169-1182. DOI: 10.12973/ejac.2017.00242a (2017).

16. B.L. Weinstein, Regional growth theories and local economic development: some examples. In: B. Johansson, C. Karlsson \& R.R. Stough (Eds.), Theories of Endogenous Regional Growth: Lessons for Regional Policies (pp. 330342). Berlin, Springer. DOI: 10.1007/978-3-642-59570-7 (2001).

17. E.Gushchina, Factors, criteria, and determinants of the increase in the effectiveness of university education in Russia. The International Journal of Educational Management, 31(4), 485-496. DOI: 10.1108/IJEM-02-2016-0038 (2017).

18. D. Valler, A. Wood, Conceptualizing local and regional economic development in the United States. Regional Studies, 44(2), 139-151. DOI: 10.1080/00343400802378768 (2010).

19. N.G. Yushkova, Improvement of tool support of the spatial approach to regional planning: problems, specifics, trends. Economic and Social Changes: Facts, Trends, Forecast, 6(36), 225-242. DOI: 10.15838/esc/2014.6.36.17 (2014).

20. R. Moreno, M. Artís, E. López-Bazo, J.Suriñach, Evidence on the complex link between infrastructure and regional growth. Working Papers of Economic Sciences, 12(1-2), 81-108 (1997).

21. E.V. Frolova, M.V. Vinichenkoa, A.V. Kirillov, O.V. Rogach, E.E. Kabanova, Development of social infrastructure in the management practices of local authorities: Trends and factors. International Journal of Environmental \& Science Education, 11(15), 7421-7430. URL: http://www.ijese.net/makale/1036 (2016).

22. G. Swinburn, S. Goga, F.Murphy, Local economic development: A primer developing and implementing local economic development strategies and action plans. Washington, D.C: World Bank \& Bertelsmann Stiftung (2006). 